\title{
EFFECT OF YOGA ON HEART RATE AND BLOOD PRESSURE IN MILD HYPERTENSIVE PATIENTS (STAGE I)
}

\author{
N. Victoria Devi' ${ }^{1}$ Sarada $N^{2}$ \\ ${ }_{1}^{1}$ Postgraduate Trainee, Department of Physiology, RIMS, Imphal. \\ 2Professor, Department of Physiology, RIMS, Imphal.
}

\begin{abstract}
BACKGROUND

Hypertension is an important public health issue and is one of the leading causes of death and disability. Yoga which aims at harmonising mind, body and spirit has been shown to be useful in individuals with hypertension.

The objective of our study is to assess the effect of Yoga on Heart Rate (HR) and Blood Pressure (BP) in mild hypertensive patients (Stage 1 of JNC 7 classification) who are not in any form of medication.

MATERIALS AND METHODS

50 mild hypertensives (28 males and 22 females) with systolic blood pressure (SBP) 140 to $159 \mathrm{mmHg}$ and/or Diastolic Blood Pressure (DBP) 90 to $99 \mathrm{mmHg}$ in the age group of 25 - 65 years, who came to practise yoga at the Yoga Training and Research Centre (YTRC bearing registration no. 38 of 1987) Kwakeithel, Imphal, were selected based on exclusion criteria. Heart rate and blood pressure were estimated before any intervention. Physiological parameters viz. HR response to standing (30:15), BP response to standing, Valsalva Ratio (VR) and Isometric Hand Grip test (IHG) were estimated to assess autonomic functions in these patients. They were subjected to yogic practices (Asanas, pranayama and meditation) for 1 hour in the morning each day for 6 days a week. After 3 months, the same parameters were estimated again.
\end{abstract}

\section{RESULTS}

We observed a statistically significant decrease in HR, SBP and DBP after 3 months of yoga training. It was also seen that 3 months of yoga training improved autonomic functions in mild hypertensives.

\section{CONCLUSION}

Mind-body therapy of yogic asanas has been found to be effective in reducing heart rate and blood pressure in mild hypertensives.

\section{KEYWORDS}

Hypertension, Yoga, Heart Rate, Baroreceptor Sensitivity, Sympathetic, Parasympathetic, Telomerase.

HOW TO CITE THIS ARTICLE: Devi NV, Sarada N. Effect of yoga on heart rate and blood pressure in mild hypertensive patients (stage I). J. Evolution Med. Dent. Sci. 2017;6(22):1754-1757, DOI: 10.14260/Jemds/2017/386

\section{BACKGROUND}

The word 'Yoga' originated from the Sanskrit word 'yuj' for union and aims at harmonising mind, body and spirit. Yoga is based on one of the six systems of Indian Philosophy that have been transmitted orally through generations. Patanjali, the father of Ayurvedic medicine, wrote a treatise called the 'Yoga Sutras' in which he formalised this discipline. Iyengar yoga, developed and popularised by BKS Iyengar, emphasised the precise use of alignment in a wide variety of asanas to derive therapeutic benefit. There are 200 different asanas used for a variety of medical conditions ranging from musculoskeletal complaints to internal organ disturbances such as hypertension, diabetes mellitus and heart diseases.[1] The gentle physical activity, slowed regulated breathing and meditation in the practice of yoga are the key elements for bringing about the physiological changes in the body.[2] Common diseases such as coronary artery disease, hypertension and diabetes mellitus are being attributed to a faulty lifestyle.

Financial or Other, Competing Interest: None.

Submission 29-11-2016, Peer Review 01-03-2017,

Acceptance 08-03-2017, Published 16-03-2017.

Corresponding Author:

N. Victoria Devi,

Department of Physiology,

RIMS, Imphal-795004, Manipur.

E-mail:drvictoriark@gmail.com

DOI: $10.14260 /$ jemds $/ 2017 / 386$

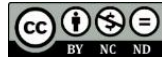

In 1990, Dean Ornish, an American cardiologist demonstrated the favourable effects of yogic lifestyle on Coronary Heart Disease (CHD). Following his demonstration, yoga is finding increasing acceptance as a nonpharmacological intervention for prevention and treatment of several diseases. [3]

Hypertension is an important public health issue worldwide and is one of the leading causes of death and disability. It is a predisposing risk factor for stroke, myocardial infarction, congestive heart failure, arterial aneurysm and chronic renal failure.[4] Several studies have shown the therapeutic benefits of yoga in the management of hypertension. The present study has been undertaken to assess the effectiveness of yoga in the management of mild hypertension (Stage I of JNC 7 classification) without medical intervention.

\section{MATERIALS AND METHODS}

The study was carried out in the Department of Physiology, Regional Institute of Medical Sciences (RIMS), Imphal, from August 2015 to August 2016 in collaboration with Yoga Training and Research Centre (YTRC bearing registration no. 38 of 1987) Kwakeithel, Imphal. 50 (fifty) mild hypertensives (28 males and 22 females) with Systolic Blood Pressure (SBP) 140 - 159 mmHg and/or Diastolic Blood Pressure (DBP) 90 $99 \mathrm{mmHg}$ in the age group of 25 - 65 years, irrespective of sex who came to practise yoga at YTRC were selected based on exclusion criteria. 


\section{Exclusion Criteria}

1. Athletes, regular yoga practitioners and patients undergoing any other form of exercise.

2. Patients on antihypertensives with/without statin therapy.

3. Patients with any other chronic illnesses like angina, stroke, uncontrolled diabetes mellitus, chronic renal failure, etc.

\section{Study Design}

It is an intervention study in which we compare the parameters between before and after yoga training in the same individual.

\section{Data Collection Procedure}

The study protocol was explained to the subjects and informed written consent was taken. Ethical clearance was sought from the Institutional Ethics Committee, RIMS, Imphal. The study parameters were recorded before starting the yoga training. The subjects practised yoga which included asanas, pranayama and meditation at the yoga centre under the guidance of a yoga instructor for one hour in the morning each day for six days a week. The same parameters were estimated again after 3 months of yoga training.

The subjects were advised to report to the Department of Physiology, RIMS, Imphal, between 9:00 am and 10:00 am and their physiological parameters were recorded. They were instructed to avoid tea, coffee or smoking for at least 6 - $8 \mathrm{hrs}$. before measuring the baseline parameters. After a rest of 15 20 minutes in a comfortable sitting posture, their physiological parameters were recorded. They were advised to wear loose fitting clothes. Tight underclothing and metallic objects were not allowed. The resting time after each test was 5 - 10 mins.

\section{Parameters Studied}

1. Resting Heart Rate- Lead II of the ECG was selected for measuring Heart Rate (HR). HR was recorded in supine position during normal quiet breathing for a period of 1 min. The average R-R interval gives the HR.

2. Resting Blood Pressure- BP was recorded with a mercury sphygmomanometer (Diamond) in the supine position in the right upper arm. Three readings were taken at an interval of 10 mins. and the average of the three values was calculated.

3. HR Response to Standing (30:15 Ratio)- After a complete rest of 10 minutes, the ECG recording was started and the subject assumed erect posture as quickly as possible within 3 seconds with continuous ECG recording. The longest $\mathrm{R}-\mathrm{R}$ interval occurring at about 30 beats after standing divided by the shortest $\mathrm{R}-\mathrm{R}$ interval occurring at about 15 beats after standing gives the result for 30:15 ratio (RR ratio).

4. BP Response to Standing- After 5 minutes' rest in the supine position, the subject was asked to stand up immediately and remain still without movement. BP was recorded after 0.5 minute, 1 minute and 3 minutes of standing.

5. Valsalva Ratio (HR Response to Valsalva Manoeuvre)- After a rest of 5 mins in the sitting position, the subject was asked to exhale forcefully with closed nostrils through the mouthpiece of a modified mercury sphygmomanometer (in which a mouth piece and a body tube of $50 \mathrm{~mL}$ disposable hypodermic syringe is connected in place of the air pump) and to maintain pressure in the manometer up to $40 \mathrm{mmHg}$ for 15 seconds. ECG recording was taken during the manoeuvre and continued for 30 seconds after the manoeuvre. The ratio of the longest $\mathrm{R}-\mathrm{R}$ interval after blowing to the shortest R-R interval during blowing gives the Valsalva ratio.

6. BP Response to Sustained Handgrip- For this, the subject was asked to perform maximum grip of the handgrip dynamometer with the dominant hand and the maximum capacity from the graduation marking was noted. After 5 minutes' rest in the sitting position, the subject was asked to hold the grip with $30 \%$ of the maximum capacity for 5 minutes. While performing this sustained handgrip, BP was recorded on the contralateral arm at 2 minutes, 4 minutes and just before the release. The average of the three readings was taken.

\section{Statistical Analysis}

Statistical analysis was done using SPSS 18 for windows. Paired ' $\mathrm{t}$ ' test was used to analyse the quantitative data and to determine the p-values. A p-value of $<0.05$ was taken as significant and interpretations were made accordingly.

\section{RESULTS}

We observed a statistically significant decrease in HR, SBP and DBP following 3 months of yoga training in mild hypertensives (stage I). We also observed an improvement in autonomic function in these patients as indicated by the results of the physiological parameters.

\begin{tabular}{|c|c|c|c|}
\hline $\begin{array}{c}\text { Test } \\
\text { Parameter }\end{array}$ & $\begin{array}{c}\text { Before Yoga } \\
\text { (mean } \pm \text { S.E.) }\end{array}$ & $\begin{array}{c}\text { After Yoga } \\
\text { (mean } \pm \text { S.E.) }\end{array}$ & $\begin{array}{c}\text { t-test } \\
\text { (p value) }\end{array}$ \\
\hline $\begin{array}{c}\text { Resting Heart } \\
\text { Rate } \\
\text { (Beats/min) }\end{array}$ & $75.02 \pm 0.34$ & $69.30 \pm 0.25$ & $0.000^{* *}$ \\
\hline RR Ratio & $1.11 \pm 0.003$ & $1.17 \pm 0.006$ & $0.000^{* *}$ \\
\hline VR & $1.35 \pm 0.01$ & $1.49 \pm 0.01$ & $0.000^{* *}$ \\
\hline \multicolumn{3}{|c|}{ Table 1. Heart Rate/RR/VR } \\
\hline
\end{tabular}

**Indicates that $\mathrm{p}$ value is highly significant $(<0.001)$

Table 1 shows the comparison of resting heart rate, heart rate response to standing (RR ratio) and Valsalva Ratio (VR) before and after yoga training. The mean resting heart rate decreases from $75.02 \pm 0.34$ beats/min to $69.30 \pm 0.25$ beats/min after yoga and the change is highly significant. It is also seen that the RR ratio increases significantly from $1.11 \pm$ 0.003 to $1.17 \pm .006$ and VR from $1.35 \pm 0.01$ to $1.49 \pm 0.01$.

\begin{tabular}{|c|c|c|c|}
\hline $\begin{array}{c}\text { Resting Blood } \\
\text { Pressure } \\
\text { (mmHg) }\end{array}$ & $\begin{array}{c}\text { Before Yoga } \\
\text { (mean } \pm \text { S.E.) }\end{array}$ & $\begin{array}{c}\text { After Yoga } \\
\text { (mean } \pm \text { S.E.) }\end{array}$ & $\begin{array}{c}\text { t-test } \\
\text { (p value) }\end{array}$ \\
\hline Systolic & $143.86 \pm 2.99$ & $135.64 \pm 0.60$ & $0.005^{*}$ \\
\hline Diastolic & $89.08 \pm 0.67$ & $84.64 \pm 0.59$ & $0.000^{* *}$ \\
\hline \multicolumn{3}{|c|}{ Table 2. Resting Blood Pressure } \\
\hline
\end{tabular}

In Table 2 resting blood pressure is compared before and after three months of regular yoga training. Both systolic and diastolic readings show significant decrease after yoga training as indicated by the significant $p$ values in the last 
column. The SBP decreases from $143.86 \pm 2.99 \mathrm{mmHg}$ to

\begin{tabular}{|c|c|c|c|c|}
\hline \multicolumn{2}{|c|}{ Blood Pressure Standing (mmHg) } & Before Yoga (mean \pm S.E.) & After Yoga (mean \pm S.E.) & t-test ( $p$ value) \\
\hline \multirow{2}{*}{$0.5 \mathrm{~min}$} & Systolic & $144.96 \pm 0.72$ & $135.28 \pm 0.63$ & $0.00^{*}$ \\
\hline & Diastolic & $88.88 \pm 0.64$ & $84.96 \pm 0.60$ & $0.00^{*}$ \\
\hline \multirow{2}{*}{$1 \mathrm{~min}$} & Systolic & $129.92 \pm 0.76$ & $125.32 \pm 0.63$ & $0.00^{*}$ \\
\hline & Diastolic & $87.12 \pm 0.57$ & $83.72 \pm 0.59$ & $0.00 *$ \\
\hline \multirow{2}{*}{3 mins } & Systolic & $146.36 \pm 0.71$ & $135.44 \pm 0.62$ & $0.00^{*}$ \\
\hline & Diastolic & $87.96 \pm 0.66$ & $84.40 \pm 0.61$ & $0.00^{*}$ \\
\hline
\end{tabular}

Table 3 shows the change in blood pressure response to standing at $0.5 \mathrm{~min}, 1 \mathrm{~min}$ and $3 \mathrm{mins}$ before and after yoga

training. All the changes are statistically highly significant as indicated by the corresponding $\mathrm{p}$ values.

\begin{tabular}{|c|c|c|c|}
\hline $\begin{array}{c}\text { BP Response to Sustained } \\
\text { Handgrip (mmHg) }\end{array}$ & Before Yoga (mean \pm S.E.) & After Yoga (mean \pm S.E.) & t-test (p value) \\
\hline Systolic & $165.32 \pm 0.94$ & $160.80 \pm 0.72$ & $0.00^{*}$ \\
\hline Diastolic & $107.66 \pm 1.57$ & $104.48 \pm 0.58$ & $0.00^{*}$ \\
\hline \multicolumn{3}{|c|}{ Table 4. BP Response to Sustained Handgrip } \\
\hline
\end{tabular}

Table 4 shows the blood pressure response to sustained handgrip before and after yoga training. The mean SBP decreases from $165.32 \pm 0.94 \mathrm{mmHg}$ to $160.80 \pm 0.72 \mathrm{mmHg}$ and the mean DBP decreases from $107.66 \pm 1.57 \mathrm{mmHg}$ to $104.48 \pm 0.58 \mathrm{mmHg}$.

\begin{tabular}{|c|c|c|c|c|c|c|}
\hline & \multicolumn{3}{|c|}{ Before Yoga } & \multicolumn{3}{c|}{ After Yoga } \\
\hline Parameter (mmHg) & Rest & IHG & \% Change & Rest & IHG & \% Change \\
\hline SBP & $143.86 \pm 2.99$ & $165.32 \pm 0.94$ & 14.91 & $135.64 \pm 0.60$ & $160.80 \pm 0.72$ & 18.54 \\
\hline DBP & $89.08 \pm 0.67$ & $107.66 \pm 1.57$ & 20.85 & $84.64 \pm 0.59$ & $104.48 \pm .58$ & 23.44 \\
\hline
\end{tabular}

Table 5. Percentage Change in Blood Pressure (Before and After Yoga)

Table 5 shows the percentage change in blood pressure response to sustained hand grip before and after yoga. In case of SBP, the percentage change increases from $14.91 \%$ to $18.54 \%$ and in case of DBP the percentage change increases from $20.85 \%$ to $23.44 \%$ after yoga training.

\section{DISCUSSION}

In our study, it is found that following three months of yoga training (Asanas, pranayama and meditation), there is significant reduction in HR, SBP and DBP. These findings are consistent with the studies of Murugesan et al,[5] Indla Devasana et al[6] and Cohen et al.[7]

The reduction in HR and increased RR ratio and VR after 3 months of yoga training show parasympathetic dominance with practice of yogasanas.[8],[9] Vagal control allows more rapid adjustment in HR than does Sympathetic Nervous System (SNS) control, which takes longer to turn on and longer to turn off.[10]

Vagal dominance is a sign that shows that stress response system has greater flexibility to respond to challenges.[11] Underactivity of the parasympathetic nervous system leads to greater dependence on sympathetic excitation of the Cardiovascular System (CVS) and other systems with negative health consequences such as hypertension, hyperarousal and over reactivity.[12]

Parasympathetic dominance after yoga training does not mean that the sympathetic response will be blunted in times of stress or emergency. As we can see in our finding, the fall in blood pressure from the baseline value in response to standing is less after yoga training. In response to Isometric
Hand Grip test (IHG) also, the percentage rise of blood pressure response is increased after yoga. In case of SBP, the percentage increase is from $14.91 \%$ to $18.54 \%$ and in case of DBP the percentage increase is from $20.91 \%$ to $23.44 \%$ as shown in Table 5 . This shows that yoga training optimises the sympathetic response to stressful stimuli like isometric handgrip test and restores the autonomic regulatory reflex mechanisms in hypertensive patients.[13]

Baroreceptor Sensitivity (BRS) is a measure of heart's capacity to efficiently alter and regulate BP in accordance with the requirements of a given situation. A high degree of BRS is thus a good marker of cardiac health. Regular practice of yoga increases the baroreceptor sensitivity (i.e. set point is lowered) and decreases the sympathetic tone thereby restoring $\mathrm{BP}$ to normal levels.[14]

Physical activity is known to lower BP. So, this could be one factor how yoga decreases the resting BP. The meditation element of yoga also has an effect in lowering BP, as it reduces anxiety and stress. Meditation also has a balancing effect on Autonomic Nervous System (ANS). One Researcher explains that meditation and music decrease sympathetic nervous system activity by sensitising the receptors in arteries, heart and lungs. But there is no clear proof to explain how relaxation lowers blood pressure exactly.[15]

Recently, it has been reported that transcendental meditation stimulates genes that produce telomerase - an enzyme linked with reduced blood pressure and mortality. Telomeres are stretches of DNA at the ends of chromosomes that protect our genetic data. Shortening of telomeres has been linked with aging, cancer and a higher risk of death. 
Telomerase is an enzyme made of protein and RNA units that elongates chromosomes by adding sequences to the ends. Transcendental meditation has shown to increase telomerase gene expression.[16]

Breathing is considered to be a regulator of ANS and consequently of mental processes as Swami Rama stated 'Controlling the breath and thus calming the nerves is a prerequisite to controlling the mind and the body. Controlled breathing exercise in the practice of yoga (pranayama) improves vagal activity and therefore decreases baseline heart rate and blood pressure.[17]

\section{CONCLUSION}

Based on our findings, it can be concluded that 3 months of yoga training has been found to be useful in reducing HR, SBP and DBP in mild hypertensives (Stage I). Data from Framingham Heart Study show that a modest decrease of 2 mmHg of DBP could reduce the risk of stroke or transient ischaemic attack by $14 \% .{ }^{[18]}$ While a $10 \mathrm{mmHg}$ reduction in SBP is associated with a $30 \%$ relative reduction in risk of stroke.[19] Pharmacological interventions are always associated with unwanted side effects. Non-pharmacological methods like yoga should be encouraged and incorporated in our daily lives for the prevention and control of hypertension.

\section{REFERENCES}

[1] Iyengar BKS. Light on yoga: yoga dipika. New York: Schoken BooKs 1966.

[2] Cohen D, Townsend RR. Yoga and hypertension. J Clin Hypertens (Greenwich) 2007;9(10):800-1.

[3] Bijlani RL, Manjunatha S. Understanding medical physiology. $4^{\text {th }}$ edn. Daryaganj (New Delhi): Jaypee Publishers 2011.

[4] Hackam DG, Khan NA, Hemmelgam BR, et al. The 2010 Canadian hypertension education program recommendations for the management of hypertension: part 2- therapy. Can J Cardiol 2010;26(5):249-58.

[5] Murugesan R, Govindarajulu N, Bera TK. Effect of selected yogic practices on the management of hypertension. Indian J Physiol Pharmacol 2000;44(2):207-10.

[6] Devasena I, Narhare P. Effect of Yoga on heart rate and blood pressure and its clinical significance. Int J Biol Med Res 2011;2(3):750-3.
[7] Cohen DL, Bloedon LT, Rothman RL, et al. Iyengar yoga versus enhanced usual care on blood pressure in patients with prehypertension to stage I hypertension: a randomized controlled trial. Evid Based Complement Alternat Med 2011;2011:546428.

[8] Telles S, Nagarathna R, Nagendra SR. Autonomic changes during "OM" meditation. Indian J Physio Pharmacol 1995;39(4):418-20.

[9] Desh D, Sinha AN, Gusain VS. A study on effects of meditation on parasympathetic nervous system functional status in meditators. Intl J Res Pharma Biomed Sci 2012;3(2):772-9.

[10] Thayer JF. Vagal tone and the inflammatory reflex. Cleve Clin J Med 2009;76(Suppl 2):S23-6.

[11] Thayer JF, Sternberg E. Beyond heart rate variability: vagal regulation of allostatic systems. Ann N Y Acad Sci 2006;1088:361-72.

[12] Thayer JF, Lane RD. A model of neurovisceral integration in emotion regulation and dyesregulation. J Affect Disord 2000;61(3):201-16.

[13] Vijayalakshmi P, Mohan M, Bhavani AB, et al. Modulation of stress induced by isometric handgrip test in hypertensive patients following yogic relaxation training. Indian $\mathrm{J}$ Physiol Pharmacol 2004;48(1):59-64.

[14] Sevalmurthy W, Sridharan K, Ray US, et al. A new physiological approach to control essential hypertension. Indian J Physio Pharmacol 1998;42(2):205-13.

[15] MacGill M. Yoga, blood pressure and health. 2016. www.medicalnewstoday.com.

[16] Ellis M. Can meditating reduce blood pressure? 2015. www.medicalnewstoday.com.

[17] Adhana R, Gupta R, Dvivedi J, et al. The influence of the 2:1 yogic breathing technique on essential hypertension. Indian J Physiol Pharmacol 2013;57(1):38-44.

[18] Whelton PK, He J, Appel LJ, et al. Primary prevention of hypertension: clinical and public health advisory from the National High Blood Pressure Education Program. JAMA 2002;288(15):1882-8.

[19] Staessen JA, Gasowski J, Wang JG, et al. Risks of untreated and treated isolated systolic hypertension in the elderly: meta-analysis of outcome trials. Lancet 2000;355(9207):865-72. 